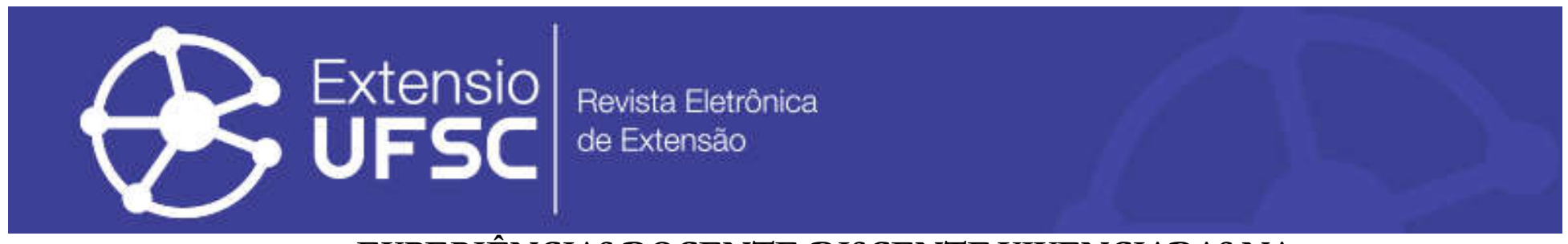

\title{
EXPERIÊNCIAS DOCENTE-DISCENTE VIVENCIADAS NA DISCIPLINA DE PROJETOS COMUNITÁRIOS DE EXTENSÃO UNIVERSITÁRIA - UNIVALI
}

\author{
Márcia Gilmara Marian Vieira \\ Universidade do Vale do Itajaí \\ mmarian@univali.br
}

Yára Christina Cesário Pereira
Universidade do Vale do Itajaí
yara@univali.br

Mariana Teixeira Fares Camargo

Universidade do Vale do Itajaî mariana.fares@gmail.com

\begin{abstract}
Resumo
O presente artigo tem como objetivo apresentar as vivências dos acadêmicos na disciplina de Projeto Comunitário de Extensão Universitária (PCEU), na Universidade do Vale do Itajaí (UNIVALI), incorporando um novo conceito de sala de aula via elaboração de miniprojetos no contexto da pandemia "COVID 19". O projeto "Educação Para Transformação: Mudando Vidas" estabeleceu diálogos com o enfrentamento de problemas sociais e econômicos contemporâneos, tais como: a inclusão da população de risco e vulnerabilidade social e busca pela segurança alimentar como uma das condições para a conquista da cidadania em sua plenitude. No período de março a junho de 2020, utilizou a metodologia baseada na Sistemática do Círculo de Cultura de Paulo Freire, por meios de Rodas de Diálogo. Os acadêmicos, por sua vez, tiveram a oportunidade de socializar os seus diferentes saberes exercendo sua cidadania, e, nesse processo, o desenvolvimento de habilidades e competências que contribuem para sua formação integral.

Palavras-chave: Educação Ambiental. Extensão Universitária. Agricultura Sustentável.

\section{TEACHER-STUDENT EXPERIENCES EXPERIENCED IN THE UNIVERSITY EXTENSION COMMUNITY PROJECTS SUBJECT - UNIVALI}

\begin{abstract}
This article aims to present the experiences of academics in the discipline of Community Project for University Extension (PCEU) at the University of Vale do Itajai (UNIVALI) incorporating a new concept of the classroom via the elaboration of mini-projects in the context of the pandemic "COVID 19 ". The project "Education for Transformation: Changing Lives", established dialogues with the confrontation of contemporary social and economic problems, such as: the inclusion of the population at risk and social vulnerability and search for food security as one of the conditions for the conquest of citizenship in its fullness. In the period from March to June 2020, using the methodology based on the Paulo Freire Culture Circle System, by means of Dialog Circles. The academics, in turn, had the opportunity to socialize their different knowledge exercising their citizenship, and in this process, the development of skills and competences that contribute to their integral formation.

Keywords: Environmental Education. University Extension. Sustainable Agriculture.

\section{EXPERIENCIAS PROFESOR-ESTUDIANTE EXPERIMENTADAS EN LA ASIGNATURA DE PROYECTOS DE EXTENSIÓN UNIVERSITARIA COMUNITARIA - UNIVALI}

\section{Resumen}

Este artículo tiene como objetivo presentar las experiencias de académicos en la disciplina de Proyecto Comunitario de Extensión Universitaria (PCEU) de la Universidad de Vale do Itajaí (UNIVALI) incorporando un nuevo concepto del aula a través de la elaboración de mini-proyectos en el contexto de la pandemia "COVID 19". El proyecto Educación para la Transformación: Cambiando Vidas, estableció diálogos con el enfrentamiento de problemas sociales y económicos contemporáneos, tales como: la inclusión de la población en riesgo y vulnerabilidad social y la búsqueda de la seguridad alimentaria como una de las condiciones para la conquista de la ciudadanía en su plenitud. En el período de marzo a junio de 2020, utilizando la metodología basada en el Sistema Círculo Cultural Paulo Freire, mediante Ruedas de Diálogo. Los académicos, a su vez, tuvieron la oportunidad de socializar sus diferentes saberes ejerciendo su ciudadanía, y en este proceso, el desarrollo de habilidades y competencias que contribuyan a su formación integral.

Palavras chave: Educación Ambiental. Extensión Universitaria. Agricultura Sostenible. 
Experiências docente-discente vivenciadas na disciplina de projetos comunitários de extensão universitária - Univali

\section{INTRODUÇÃO}

O presente artigo é parte fundante das experiências da docência-discência vivenciadas na disciplina de Projetos Comunitários de Extensão Universitária (PCEU), da Universidade do Vale do Itajaí (Univali), que foi incorporada na matriz curricular de diferentes cursos que compõem o Núcleo de Disciplinas Institucionais (NID), tendo como objeto a formação dos acadêmicos em atividades extensionistas e assim possibilitando novos tempos e espaços de formação viabilizadora de uma práxis crítico-emancipadora. Essa poderá vir a ser desenvolvida por ações extensionistas de concepção acadêmica, processual e orgânica, conforme Reis (1989).

Ressalta-se que a extensão articulada ao ensino e à pesquisa na direção da formação integral dos sujeitos que frequentam a universidade deve ser parte integrante do projeto institucional e dos Projetos Políticos Pedagógicos dos cursos de graduação e pós-graduação, bem como dos programas de capacitação docente. Enfim, que ela irrigue institucionalmente os cursos e não se torne apenas um grupo de ações isoladas.

Dessa forma, a ampliação da dimensão do ensino para a inserção dos(as) acadêmicos(as) em espaços educativos para além da sala de aula precisa ser considerada, para que se abram espaços para novas experiências por meio da investigação e da ação, na perspectiva da pesquisa e da extensão, dando outro sentido ao processo de aprendizagem, "fazendo com que a universidade idealizada, não ilusória, cumpra o seu papel não de resolvedora ou mitigadora das dores da sociedade, mas de geradora de uma sociedade mais justa, mais equânime, mais sustentável” (OLIVEIRA; GARCIA, 2011, p. 160).

É nessa perspectiva que as Vice Reitorias de Graduação e Desenvolvimento Institucional e de Extensão e Assuntos Comunitários da Univali criaram a disciplina de PCEU, inserida na matriz curricular de todos os cursos de graduação em diferentes Escolas do Conhecimento. Trata-se da primeira estratégia da curricularização da extensão institucionalizada pela Univali, em 2019.

Nessa disciplina, enquanto proposta inovadora da Universidade, o(a) acadêmico(a) tem a oportunidade de aprender sobre a elaboração de projetos comunitários que contribuam com a melhoria da qualidade de vida das comunidades, fomentando o desenvolvimento de uma atitude profissional e cidadã e a formação de profissionais comprometidos com o desenvolvimento sustentável.

Para início de conversa na disciplina de PCEU, os(as) acadêmicos(as) foram estimulados a compreender a historicidade da extensão universitária no Brasil, com a intenção 
Experiências docente-discente vivenciadas na disciplina de projetos comunitários de extensão universitária - Univali

de compreenderem e se apropriarem da concepção vigente das ações e da curricularização da extensão. A inclusão da extensão no contexto do currículo passou a ser entendida como retroalimentadora de atividades de ensino-aprendizagem e lócus de integração ensino-pesquisa, fazendo emergir um novo conceito de sala de aula - todos os espaços fora e dentro da Universidade são espaços educadores.

A etapa seguinte apresentou aos acadêmicos(as) um dos projetos de extensão da Escola do Mar, Ciência e Tecnologia - EMCT/ Univali - "Educação para Transformação: meio ambiente e saúde". O referido projeto tem como propósito apresentar as diferentes estratégias adotadas para a manutenção dos modos de produção nos espaços rurais e urbanos, com o fito de alcançar a autonomia e o empoderamento das mulheres agricultoras dentro da agroecologia (VIEIRA et al., 2019).

O percurso metodológico proposto para a disciplina de PCEU iniciou com a apresentação do projeto de extensão "Educação para Transformação: meio ambiente e saúde", da EMCT, com a intenção de estabelecer laços entre diferentes disciplinas da matriz curricular, entre diversos contextos socioculturais e econômicos e com os traços inquietantes do emaranhado de fios das diversas experiências de vida dos(as) acadêmicos(as).

O projeto em referência funcionou como uma espécie de "guarda-chuva" para a elaboração de miniprojetos. Tal procedimento metodológico vem ancorado na concepção de interdisciplinaridade de Nicolescu (2005, p.52), que a descreve como a "[...] transferência de métodos de uma disciplina para outra". E, no processo de transferência, a apropriação do conhecimento, pela busca, seleção, organização e apropriação de uma base conceitual que possibilita a compreensão das dimensões da sustentabilidade: cultural, social, econômica, politica e ambiental.

Para complementar o percurso metodológico da disciplina de PCEU foi sugerido a criação de miniprojetos, apresentados e detalhados nos Materiais e Métodos.

Diante do exposto, é possível inferir que o objetivo deste artigo é apresentar as experiências da docência-discência vivenciadas na disciplina PCEU/Univali, incorporando um novo conceito de sala de aula via elaboração de miniprojetos de extensão, elaborados e executados no contexto da Pandemia da "COVID-19".

\section{MATERIAIS E MÉTODOS}

A metodologia baseou-se na sistemática do Círculo de Cultura de Paulo Freire, por meio de Rodas de Diálogo que proporcionam autonomia por meio da participação livre e crítica para uma aprendizagem efetiva (FREIRE, 2020). 
Experiências docente-discente vivenciadas na disciplina de projetos comunitários de extensão universitária - Univali

No período de 26 de março a 02 de julho de 2020 (quintas-feiras, das $19 \mathrm{~h}$ às $22 \mathrm{~h} 30$ ) os encontros teórico-práticos da disciplina de PCEU aconteceram via web conferências, por meio da Plataforma do Ambiente Blackboard, usando-se o sistema de aulas remotas para dar visibilidade e amplitude para a comunidade acadêmica sobre as possibilidades e compartilhamentos da Extensão Universitária e, assim, entender a importância das vivências da Universidade junto às comunidades locais. Importante e engrandecedor foram as experiências vivenciadas, as trocas de saberes e o empoderamento dos(as) participantes durante o período de distanciamento espacial devido à pandemia.

O PCEU contemplou acadêmicos(as) do $1^{\circ}$ período dos cursos de Pedagogia, Licenciatura em Letras e em História; Nutrição; Fisioterapia; Odontologia; Marketing e Engenharia Mecânica; um grupo interdisciplinar formado por 44 acadêmicos.

Os vídeos O que é Extensão Universitária? e Diretrizes para as Políticas de Extensão da Educação Superior Brasileira foram propostos como atividade inicial, seguidos de problematizações e reflexões sobre as temáticas.

Foram apresentados os Objetivos de Desenvolvimento Sustentável (ODS) que compõem a agenda mundial adotada durante a Cúpula das Nações Unidas sobre o Desenvolvimento Sustentável (ONU), em setembro de 2015, composta por 17 objetivos e 169 metas a serem atingidos até 2030. Nessa agenda estão previstas ações mundiais nas áreas de erradicação da pobreza, segurança alimentar, agricultura, saúde, educação, igualdade de gênero, redução das desigualdades, energia, água e saneamento, padrões sustentáveis de produção e de consumo, mudança do clima, cidades sustentáveis, proteção e uso sustentável dos oceanos e dos ecossistemas terrestres, crescimento econômico inclusivo, infraestrutura, industrialização, entre outros.

Nas aulas seguintes, a professora da disciplina apresentou os 57 projetos de extensão e os 10 programas que a Univali tem atualmente em execução nas diversas áreas e diferentes Escolas do Conhecimento. Contou-se com a parceria de dois colegas docentes e bolsistas extensionistas que apresentaram suas experiências e vivências em projetos de diversas áreas. Três projetos da EMCT/UNIVALI foram apresentados de forma mais detalhada. A saber:

O primeiro projeto foi Educação para Transformação: Meio Ambiente e Saúde; este desenvolve o trabalho multicêntrico e interdisciplinar, assim como fortalece, incentiva, valoriza e dá visibilidade a práticas que contribuam para o alcance dos ODS/ONU. O público-alvo são mulheres da região do Vale do Itajaí, atendendo também docentes, professores e alunos das escolas estaduais da $17^{\mathrm{a}}$ Coordenadoria Regional de Educação (CRE) de Itajaí (SC) e comunidade em geral. Integrando ações educativas de pesquisa, ensino e extensão, o objetivo geral é promover educação popular em saúde e meio ambiente para o desenvolvimento social, 
Experiências docente-discente vivenciadas na disciplina de projetos comunitários de extensão universitária - Univali

econômico e ambiental da agricultura sustentável, estimulando a participação cidadã como estratégia de mudança e autonomia.

Depois o projeto Água Viva, do Recurso ao Patrimônio que visa à popularização de conhecimentos sobre a qualidade e a importância da água para as comunidades da região de abrangência da bacia hidrográfica do Rio Itajaí-Açú, e dos Rios Tijucas e Biguaçu. As atividades envolvem cursos de capacitação, oficinas, palestras expositivas e dialogadas, visitas de estudo e intervenções artísticas. O projeto trabalha desde 2015 para a compreensão e legitimação da água enquanto "patrimônio natural", bem como a responsabilidade de todos na sua preservação.

E para finalizar essa aula, foi apresentado o projeto Empreenda-se Jovem, novo projeto que promete formar jovens empreendedores, por meio de ações de ensino de qualidade.

Em seguida, o desafio proposto aos(as) acadêmicos(as) foi a escolha de um dos projetos de extensão da Univali e a produção de um audiovisual como etapa de fixação dos conhecimentos. Foram realizadas entrevistas, leituras de artigos e textos, contato com os(as) professores(as) responsáveis pelos projetos. O vídeo produzido foi apresentado nas aulas remotas para todo o grupo.

Uma das aulas práticas sugeridas para os acadêmicos foi a participação em live organizada pela coordenadora do Projeto de Extensão Educação para Transformação: Meio ambiente e Saúde e professora da disciplina. A Conferência Virtual foi "Agricultura Urbana e Políticas Públicas: Desafios e Possibilidades a partir do que temos". Nesse evento virtual participaram mais de mil pessoas de diversas cidades, estados e até mesmo países diferentes no qual destacamos: Florianópolis, Balneário Camboriú, Itajaí, Blumenau, Navegantes, Brusque, Camboriú, Guabiruba, São José, Rio do Sul, Paulo Lopes, Palhoça e Chapecó (diversos municípios de SC); Erechim (RS); Pirapozinho, Teodoro Sampaio (SP); Ituiutaba (MG); Rio de Janeiro (RJ); também participantes do México e Uruguai.

Depois dessas experiências vivenciadas e o entendimento sobre o processo de extensão no contexto da universidade, foi proposto aos acadêmicos que criassem e executassem "os seus" projetos de extensão (miniprojetos) sobre um assunto/temática que fosse de relevância para a comunidade e de preferência que estivesse atrelado a um projeto já existente, contemplando a cartilha dos ODS. Foram elaborados dez mini projetos em diferentes áreas. No presente artigo, será relatado a prática de um deles.

Sete acadêmicas de diferentes cursos de graduação formaram um dos grupos e elaboraram o Projeto de Extensão “Educação para a Transformação: Mudando Vidas”. Como 
Experiências docente-discente vivenciadas na disciplina de projetos comunitários de extensão universitária - Univali

já foi explicitado, esse é vinculado ao "Educação para a Transformação: meio ambiente e saúde”, o qual pauta-se pelo tripé: ensino, pesquisa e extensão e, nesta última área, desenvolve vários projetos em consonância com o contexto social, político e econômico local e regional.

O projeto "Educação para a Transformação: Mudando Vidas" teve o intuito de adaptar as ações para um público de jovens estudantes de uma Escola Estadual de Itajaí (182 participantes) e refletir sobre as questões ambientais e de sustentabilidade, promovendo o empoderamento dos jovens estudantes, suas famílias e professores, e a liberdade para a transformação do território, considerando que essas pessoas podem ser multiplicadoras na disseminação de informação e conhecimento.

Para as acadêmicas, o maior desafio foi alcançar e sensibilizar os estudantes da Escola de Educação Básica Paulo Bauer em época de reclusão social. Todo o processo foi pensado e organizado para atingir de forma online, não apenas os estudantes, mas os professores e seus familiares.

A primeira etapa foi conversar com a supervisora da EEB Paulo Bauer, que, por sua vez, entrou em contato com a diretoria da Coordenadoria Regional de Educação (CRE), em especial com a coordenadora dos Núcleos de Educação Ambiental nas Escolas - COM-VIDA e do Grupo de Trabalho de Educação Ambiental da Região Hidrográfica 07 (GTEA RH07), de Santa Catarina. Dos diálogos, resultou a aprovação da execução do referido projeto em tempos de Pandemia da COVID-19. Trâmites não tão fáceis, pois precisaram ser analisados com rigor, mas depois de um tempo foram aprovados.

No dia 10/06, um vídeo com apresentação do grupo responsável pela elaboração do projeto sob a supervisão da professora responsável pela disciplina PCEU foi enviado à supervisora.

Logo em seguida, decidiram junto aos gestores e professores agendar uma live para apresentação do projeto para os estudantes e seus familiares. Todo o processo de organização foi realizado pela supervisora da escola e as professoras das disciplinas das oitavas séries de Ensino Fundamental II e dos primeiros anos do Ensino Médio, de Ciências e Biologia. A live transcorreu no dia 26 de junho de 2020, com a participação da supervisora, das professoras da Escola, estudantes, familiares e a professora responsável pela disciplina PCEU e as acadêmicas que elaboraram e executaram as atividades extensionistas - o total de pessoas que participou da live, 47, foi disponibilizado no canal do YouTube.

No dia 29 de junho, foi exibido pela escola o primeiro vídeo - Agrotóxicos - aos estudantes, versando sobre a questão dos "Agrotóxicos: perguntas e respostas". Esse foi elaborado de uma maneira didática, com duas das acadêmicas realizando um bate-papo, onde 
Experiências docente-discente vivenciadas na disciplina de projetos comunitários de extensão universitária - Univali

uma delas perguntava e a outra dava as respostas sobre os malefícios dos agrotóxicos para a saúde das pessoas e o meio ambiente.

O segundo vídeo - Como utilizar garrafa pet para fazer compostagem caseira - foi apresentado no dia 06 de julho, e abordava ações sobre "Como fazer Compostagem Caseira reutilizando garrafa pet", utilizando-se de apresentação visual, com explicações simples para fácil compreensão, e mostrando, para isso, a utilização de terra, grama e resíduos orgânicos sólidos como insumos.

$\mathrm{Na}$ sequência de vídeos - Mudas de alface -, uma das acadêmicas do curso de Pedagogia, que tem como profissão a agricultura e produção de hortícolas, realizou o terceiro vídeo na sua propriedade, falando sobre "Como Plantar Mudas de Alfaces". Trouxe uma vivência cotidiana, mas que, para os estudantes, revelou-se como uma maneira de incentivar o cultivo dos seus próprios alimentos.

Finalizando a série de vídeos - Hortas em espaços pequenos -, para a execução do projeto, a acadêmica do curso de Licenciatura em Letras elaborou outro falando de "Hortas em Pequenos Espaços". Hoje é uma tendência da população produzir alimentos em vasos e materiais recicláveis, como garrafas pet, então, ela mostrou como plantar manjericão, uma planta medicinal e aromática muito utilizado, cujas mudas são plantadas através de "estacas".

Outra acadêmica do curso de Marketing decidiu elaborar dois flyers sobre "Como fazer Mudas de Hortelã e Manjericão em Casa”, em que demonstrou o passo a passo de cada cultivo dessas plantas medicinais populares - flyer 1 e flyer 2 .

A cada vídeo, as acadêmicas elaboraram e enviaram questionários utilizando o aplicativo do Google Forms, com o intuito de receber um feedback das atividades online, o link 1; link 2; link 3 e link 4 . O método utilizado nos questionários foi o de amostras mistas, com perguntas subjetivas e objetivas, com o intuito de receber o resultado e as percepções dos estudantes.

Em tempos de distanciamento espacial devido à pandemia da COVID-19, o diálogo por meio de recursos audiovisuais continua sendo um recurso digital de aproximação entre os atores de um processo de construção de conhecimento. Para Paulo Freire, o diálogo é elemento central do processo de libertação e construção dos sujeitos. Os espaços de expressividade, de fala e de escuta, são os que possibilitam a construção do conhecimento, a problematização, a consciência e a criação da cultura e do mundo. Existe, nessa perspectiva, um papel ativo, uma responsabilidade de quem pertence à comunidade, em recriá-la. Por isso, ele afirma: 
Experiências docente-discente vivenciadas na disciplina de projetos comunitários de extensão universitária - Univali

"Falar do dito não é apenas redizer o dito, mas reviver o vivido que gerou o dizer que agora, no tempo do redizer, de novo se diz. Redizer, falar do dito, por isso envolve ouvir novamente o dito pelo outro sobre ou por causa do nosso dizer" (FREIRE, 1992, p. 17).

$\mathrm{Na}$ ação educativa, o exercício do diálogo precisa ser vivido pelos sujeitos como escuta do mundo do outro. Não se trata de uma escuta no sentido informativo somente, para saber coisas. Trata-se de uma presentificação do mundo do outro no meu mundo. E isso exige abertura dos sujeitos participantes do diálogo. Trata-se de um confronto de realidades em que, quem escuta, ao escutar o outro, também se escuta, se pergunta sobre seu papel e responsabilidade nesta relação comunicativa que constrói o mundo. Daí o diálogo passa a ser existencial e, por isso, transformador e criador (DALMOLIN, et al., 2018).

A partir desse pressuposto, as instituições comunitárias de ensino superior podem nortear ações diante da estratégia 12.7 do Plano Nacional de Educação (PNE), que define a integralização de, no mínimo, dez por cento do total de créditos curriculares exigidos nos cursos de graduação, por meio de programas e projetos de extensão em áreas de pertinência social, o que desafia as instituições de ensino superior brasileiras a repensarem suas concepções e práticas extensionistas, o currículo e a própria universidade (BRASIL, Lei 13.005, 2014). Mais do que a integração da extensão ao currículo/curricularização, o que se pretende é a efetiva indissociabilidade extensão-pesquisa-ensino.

Ao relacionar-se de forma dialógica e recíproca com a comunidade, a universidade exercita o trabalho intelectual compartilhado. A intelectualidade é exercício com o outro (sujeito ou meio) pelo diálogo. Nesse sentido, os sujeitos envolvidos na ação extensionista aprendem não apenas os dados informados na relação de reciprocidade, mas também o processo no qual se envolvem.

Assim, a universidade, por meio da indissociabilidade, tem um papel essencial a desempenhar, no sentido de estar vinculada a sujeitos que pensam, que constroem conhecimento e que atuam de forma indissociável. Nesse sentido, para que aconteça a indissociabilidade, é necessário que os sujeitos educativos superem as diversas formas desintegrativas e conduzam um processo mais sistêmico e integrado (SÍVERES; MENEZES, 2011, p. 53).

Nesta perspectiva, a Extensão integra elementos essenciais no/do processo de ensino e aprendizagem: o aluno, o professor e a comunidade. Comunidade que não seja compreendida como receptora dos saberes da universidade, mas que possa construir "com" a universidade um conhecimento sob a ótica dos fazeres e dos saberes dentro e fora do espaço acadêmico. 
Experiências docente-discente vivenciadas na disciplina de projetos comunitários de extensão universitária - Univali

\section{RESULTADOS E ANÁLISES}

Um dado importante para o registro é que, no primeiro semestre de 2020, foram oferecidas 10 turmas da disciplina de PCEU, e uma dessas turmas denominada de Turma 4 é a referência para apresentação dos relatos sobre o percurso de ensino e aprendizagem - extensão. Dentre as ações planejadas e vivenciadas no projeto "Educação para Transformação: Mudando Vidas apresenta-se:

Diálogo interativo com o público alvo da Escola de Educação Básica Paulo Bauer, por meio de uma live moderada pela supervisora Janine Kalkmann e pelas professoras Kátia Galbi da Costa e Anna Cláudia Oliveira. No primeiro momento, a supervisora fez uma apresentação sobre a Com-Vida (Comissão de Meio Ambiente e Qualidade de Vida na Escola) e, em seguida, a live foi conduzida pela professora da disciplina de PCEU e as acadêmicas. O tema abordado foi o uso da agricultura convencional e a transição para a agroecologia. Foi realizado o convite para a integração ao projeto ligado à disciplina de PCEU - "Educação para Transformação: Mudando Vidas”. Nesse cenário se deu a participação da acadêmica M. T. F., tecendo diálogos sobre os malefícios causados pelos agrotóxicos na saúde e no meio ambiente; a necessidade da reclusão social neste momento de pandemia; a importância da segurança alimentar e o cultivo de alimentos em pequenos espaços, uma ação que pode ser considerada uma terapia, benéfica para a saúde e segurança alimentar.

A acadêmica, B. T. continuou discorrendo sobre como os agrotóxicos podem contaminar os cultivos e a água potável trazendo muitos malefícios para a saúde das pessoas, e M. T. F. complementou ressaltando que, infelizmente, o Brasil é o maior consumidor de agrotóxicos do mundo.

A professora da disciplina interveio nessa fala e salientou que hoje, no Brasil, de acordo com a Portaria do Ministério da Saúde no 2914 de 2011, podem estar presentes 27 agrotóxicos em um copo de água e ainda essa pode ser considerada "potável”, desde que esteja dentro dos valores máximos de resíduos estabelecidos no Brasil (denominado Valor Máximo Permitido VMP), mas esse VMP está muito além do que a Europa permite. Salientou que, do total de 27 agrotóxicos aceitos na água dos brasileiros, 21 estão proibidos na União Europeia devido aos riscos que oferecem à saúde e ao meio ambiente (BRASIL, 2012a).

Outro assunto abordado pela acadêmica E. M. foi sobre a compostagem e os benefícios de transformar resíduos sólidos orgânicos em adubo para as plantas. Aponta a acadêmica que a educação ambiental é primordial e que os jovens são o futuro do país. Sua colega M. T. F. complementou dizendo que o resultado da compostagem é primordial nos 
Experiências docente-discente vivenciadas na disciplina de projetos comunitários de extensão universitária - Univali

cultivos, mas principalmente para o planeta, pois a comida tem que ter uma ciclagem. Acreditase que a implementação das composteiras como proposta de educação ambiental favorece uma mudança da realidade atual dos aterros sanitários, transforma os alunos em protagonistas do processo de sustentabilidade, além de terem um ganho de cidadania e percepção mais genuína da relação entre sujeito e meio ambiente. A compostagem como uma pedagogia participativa e eficiente para o gerenciamento dos resíduos e as vantagens que a técnica apresenta na complementação dos processos de reciclagem e na utilização do adubo nas hortas socioeducativas. Destaca-se que as vivências de compostagem experienciadas pelas mulheres agricultoras participantes do projeto Educação para Transformação possibilitaram que mais de duzentas toneladas de resíduos sólidos orgânicos não fossem para os aterros sanitários, desta maneira, diminuindo o acúmulo, podendo minimizar impactos ambientais negativos e evitando que gases tóxicos fossem gerados. Indo ao encontro da perspectiva da Agenda 2030, as ações realizadas contribuíram para os seguintes números dos Objetivos de Desenvolvimento Sustentável: 2, 3, 4, 5, 8, 10, 12 e 15.

Finalizando, a acadêmica I. S. reiterou a relevância da produção de alimentos dentro das cidades, em espaços como escolas, universidades, praças e terrenos baldios, reiterando que a agricultura urbana (AU) tem o potencial social e a possibilidade de melhoria na qualidade dos alimentos ingeridos pelas pessoas, especialmente crianças, idosos e gestantes, e também uma alternativa de renda e emprego para os habitantes.

A AU tem se expandido mundialmente, em resposta a vários desafios que se colocam às sociedades urbanas contemporâneas. Atualmente, é promovida e apoiada especialmente pela Organização das Nações Unidas para Agricultura e Alimentação (FAO), que a reconhece como uma ferramenta eficaz para responder aos desafios da segurança alimentar e à sustentabilidade urbana (MOUGEOUT, 2000).

Após as discussões e falas, uma das professoras da EEB Paulo Bauer apresentou fotos da horta escolar e que nesse momento de distanciamento espacial está sem manejo e cuidado, mas que esse é um projeto que todos precisam se envolver e praticar as atividades relacionadas à AU.

Para encerramento da live, a professora de PCEU ressaltou que a agricultura é uma arte milenar, e que agrotóxico é veneno, que outros termos como defensivos agrícolas ou pesticidas são termos usados com interesses comerciais. Destaca-se que a horta se caracteriza como um importante espaço para o desenvolvimento de atividades de Educação Ambiental em Agroecologia, pois propicia aos participantes e beneficiários possibilidades de interagir e de se integrar com o meio ambiente, tendo a horta como lócus gerador de transformação social, a 
Experiências docente-discente vivenciadas na disciplina de projetos comunitários de extensão universitária - Univali

partir da articulação entre os princípios da vida, da diversidade, da complexidade e da transformação. Assim, a horta torna-se um laboratório de aprendizado de conceitos muitas vezes abstratos em sala de aula, pois oferece estímulos e subsídios para uma maior integração entre os conhecimentos disciplinares, constituindo um lugar de transversalidade e de indissociabilidade entre Extensão, Pesquisa e Ensino.

Essa experiência realizada com a comunidade da EEB Paulo Bauer teve o intuito de promover reflexões e sensibilizações das concepções sobre os malefícios dos agrotóxicos, os benefícios da compostagem e produção de alimentos saudáveis. Em seguida, a equipe seguiu com as próximas atividades e o envio dos vídeos elaborados. Sabendo que a conquista e a confiança da comunidade por meio de um projeto de extensão necessita de tempo e dedicação, até ser possível uma mudança concreta em termos de educação em alimentação saudável e educação ambiental na comunidade.

Foi possível perceber o quanto os jovens ficaram impressionados e motivados diante do cenário apresentado. Tal impressão se fez sentir por uma fala recorrente de que "não queremos alimentos contaminados por agrotóxicos, vamos buscar aprender a cultivar alimentos limpos e que permitam uma vida saudável e um ambiente sem contaminações".

Percebeu-se que os diálogos possibilitaram a inserção da temática de educação ambiental agroecológica no contexto da educação formal. Além disso, sensibilizou essa comunidade com iniciativas e ações voltadas à gestão dos resíduos sólidos orgânicos e realização de hortas em pequenos espaços.

$\mathrm{Na}$ opinião dos entrevistados, o método de cultivo agroecológico apresenta vantagens, favorece os investimentos e também os recursos ambientais e, por se tratar de produtos com cultivo orgânico, beneficiam a saúde dos envolvidos.

No questionário analisado sobre a Compostagem e os benefícios ambientais para promover a redução do lixo orgânico gerado na escola e nas residências e serviços de jardinagem, o método que priorizamos foi o da Composteira de Leira, conhecido como "Método UFSC de compostagem". O sistema de compostagem pretende auxiliar na adubação orgânica dos canteiros, um sistema de produção de adubo orgânico que também deverá ser mantido na Escola e disseminado para outros polos, além de representar uma ferramenta educativa para a comunidade escolar.

A partir das categorias analisadas pode-se perceber que 88\% entenderam a importância da gestão dos resíduos sólidos orgânicos, que não é "lixo" e deve entrar para um processo de ciclagem dos alimentos. 64\% dos participantes disseram que já tinham ouvido falar em compostagem, mas que não sabiam exatamente como era o processo da degradação dos 
Experiências docente-discente vivenciadas na disciplina de projetos comunitários de extensão universitária - Univali

resíduos e tinham alguns preconceitos a respeito do assunto, pois acreditavam que gerava odores ruins e atraía vetores.

Teve predomínio dos estudantes $(57 \%)$ nas respostas relacionadas ao espaço para a produção de hortas, com $28 \%$ respondendo que podem plantar em vasos e cultivar alguns temperos e chás. Quando foram questionados sobre o interesse em produzir o seu próprio alimento, $60 \%$ dos participantes pretendem iniciar sua horta e $82 \%$ acham que pode ser uma atividade interativa dentro das famílias e escolas e que isso pode trazer muitos benefícios de integração e motivação. Segue a fala de alguns estudantes:

“Tivemos uma horta quando nós morávamos em casa, quanto à diversão discordo, já que é um saco ficar cuidando de plantas” (Aluno 1).

“Sim, porque na minha opinião devemos começar essa iniciativa juntos, além de juntar as famílias e ter um tempo de descontração, estaremos fazendo algo que ajude o meio ambiente, se toda família estiver apoiando você para que ocorra essa mudança, terá grande chance de que tudo dê certo" (Aluno 2).

'Sim, acho muito interessante, além de estimular o trabalho em equipe e a responsabilidade acho que deveriam trabalhar isso nas escolas" (Aluno 3).

Sobre a pergunta "Qual seria a melhor coisa de ter uma horta plantada em casa?", nesse caso 38\% responderam que seria ter alimentos sem agrotóxicos e ter uma vida saudável, $17 \%$ responderam que seria economizar dinheiro e apenas $2,0 \%$ responderam que já plantam seus próprios alimentos, algumas falas:

"Além da melhoria na saúde ainda podemos ter o cuidado necessário com aquilo que vamos comer, pois nós cultivamos, cuidamos, então sabemos o que estamos colhendo e comendo. Hoje em dia compramos coisas com tantos conservantes e outras coisas, que não temos nem mais controle daquilo que comemos" (Aluno 4).

O feedback evidenciou que os alunos (faixa etária entre 14-16 anos) prestavam atenção ao que estamos dizendo, mas estão também chegando às suas próprias conclusões sobre como é importante pensar em alimentos saudáveis e formas de obtê-los. Os alunos estão interessados e querem fazer parte da mudança, mas também nota-se que eles buscam maneiras de unir as famílias, muitas questões destacavam o fato "a família unida”, "juntar a família”.

As práticas relatadas neste artigo contribuíram com os ODS, principalmente com os objetivos 3, 11 e 12. Desta forma, é possível concluir que a agricultura urbana e periurbana produz serviços ambientais, segurança e soberania alimentar e devem ser apoiadas por meio de políticas públicas. 
Experiências docente-discente vivenciadas na disciplina de projetos comunitários de extensão universitária - Univali

Por fim, sem concluir, registra-se que as trocas de saberes e o empoderamento proporcionado pela apropriação do conhecimento durante o período de distanciamento espacial em função da pandemia da COVID 19 superaram as expectativas iniciais dos participantes do processo. Tal percepção vem ao encontro do pensar de Pereira (2004), quando diz que, no âmbito do ensino superior, é preciso criar a possibilidade de invadir novos horizontes e espaços de construção do conhecimento, possibilitando ao acadêmico(a) a aquisição de uma progressiva autonomia em sua formação, o desenvolvimento da capacidade de reflexão crítica e a promoção de troca de diferentes saberes interconectados entre os atores do processo.

\section{CONSIDERAÇÕES FINAIS}

A extensão universitária vivenciada no contexto da disciplina PCEU como possibilidade de curricularização da mesma traz para as entranhas da universidade um elemento essencial: a sociedade, fortalecendo efetivamente o tripé Ensino-Pesquisa-Extensão.

Infere-se que a disciplina de PCEU possa se tornar um "sujeito de mudança" no papel assistencialista histórico da extensão universitária no Brasil, contribuindo mais significativamente para a busca de soluções para a minimização das demandas sociais contemporâneas. A extensão passa a ser compreendida como um processo educativo que também gera a apropriação do conhecimento científico fora e dentro dos muros da universidade.

Os(as) acadêmicos(as), por sua vez, passam a ter a oportunidade de socializar os seus diferentes saberes exercendo sua cidadania. E, nesse processo, o desenvolvimento de habilidades e competências contribui para a formação integral do(a) acadêmico(a), um sujeito autônomo, sensível às problemáticas socioambientais do seu entorno, que saiba pensar e agir de forma argumentada, consciente de suas responsabilidades, capaz de ponderar sobre as consequências das suas escolhas.

Projetos como o Educação para a Transformação: Mudando Vidas têm potencial de mobilizar diferentes grupos sociais, em espaços urbanos e periurbanos, interessados em refletir a respeito da qualidade de vida, conhecer abordagens participativas de Educação Ambiental, implantar ações relacionadas aos ODS, ressignificar espaços de aprendizagens quanto à sustentabilidade, cooperação, solidariedade, alteridade, colaboração.

A experiência docência-discência vivenciada nos possibilita inferir que a disciplina PCEU pode consolidar-se como tempo e espaço para investigar, socializar, trocar e conhecer 
Experiências docente-discente vivenciadas na disciplina de projetos comunitários de extensão universitária - Univali

ideias e estratégias metodológicas que se caracterizem como um processo educativo que articula ao ensino a pesquisa e a extensão, de forma indissociável e que viabiliza a relação transformadora entre a universidade e a sociedade. No dizer de Saviani (1987, p.48), vir a ser “[...] numa força viva capaz de elevar o nível cultural geral da sociedade”. Essa é a nossa aposta.

\section{REFERÊNCIAS}

BRASIL. Lei 13.005, de 25 de junho de 2014. Aprova o Plano Nacional de Educação - PNE e dá outras providências. Disponível em: http://www.planalto.gov.br/ccivil_03/_Ato20112014/2014/Lei/L13005.htm. Acesso em: 20 junho 2020.

BRASIL. Ministério da Saúde. Documento Base de Elaboração da Portaria MS no 2.914/2011. Brasília, 2012a.

DALMOLIN, B.; SILVA, M.; VIEIRA, A. Bases pedagógicas para pensar a curriculização da extensão. In: Extensão Universitária: Perspectivas de Aprendizagem e Sentidos na Educação superior. Revista Interdisciplinar de Extensão, 2018. v.2, n.4. Disponível em: http://periodicos.pucminas.br/index.php/conecte-se/article/view/18298. Acesso em: 25 jul. 2020 .

FLORIANÓPOLIS . Decreto $\mathbf{n}^{\mathbf{0}} \mathbf{1 7 . 6 8 8}$, de 05 de junho de 2017. Dispõe sobre a criação do programa municipal de agricultura urbana. Leis Municipais. Florianópolis, SC, 2017.

Disponível em: https://leismunicipais.com.br/a/sc/f/florianopolis/decreto/2017/1769/17688/decreto-n17688-2017-dispoe-sobre-a-criacao-do-programa-municipal-de-agricultura-urbana?q=17688. Acesso em: 28 jul. 2020.

FLORIANÓPOLIS. Lei n⿳ 10.392, de 06 de junho de 2018. Dispõe sobre a política municipal de agroecologia e produção orgânica de Florianópolis (PMAPO). Leis Municipais. Florianópolis, SC, 2017. Disponível em: https://leismunicipais.com.br/a/sc/f/florianopolis/lei-ordinaria/2018/1040/10392/leiordinaria-n-10392-2018-dispoe-sobre-a-politica-municipal-de-agroecologia-e-producao-orgnica-de-florianopolis-pmapo?q=Lei $+\mathrm{n} \% \mathrm{C} 2 \% \mathrm{BA}+10.392$. Acesso em: 28 jul. 2020.

FREIRE, P. Pedagogia da Autonomia: saberes necessários à prática educativa. Rio de Janeiro: Paz e Terra, 1992. 17 p.

FREIRE, P. Educação como prática da liberdade. Rio de Janeiro: Paz e Terra, 2000.

INTERNATIONAL FINANCE CORPORATION E COLABORADORES, Segurança Alimentar e Nutricional: A contribuição das empresas para a sustentabilidade das iniciativas locais. São Paulo, 2003. p. 8

MOUGEOUT, L. Urban Agriculture: Concept and Definition. In: Urban Agriculture Magazine, Leusden, RUAF Foundation, 2000. Disponível em: https://idl-bnc- 
Experiências docente-discente vivenciadas na disciplina de projetos comunitários de extensão universitária - Univali

idrc.dspacedirect.org/bitstream/handle/10625/26429/117785.pdf?sequence=12. Acesso em: 20 jul. 2020.

NICOLESCU, B. O manifesto da transdisciplinaridade. 3.ed. São Paulo: Triom, 2005.

OLIVEIRA, T.; GARCIA, B. Extensão e indissociabilidade. In: Transcedendo Fronteiras A Contribuição da Extensão das Instituições Comunitária de Ensino Superior. Santa Cruz do Sul: Edunisc, 2011. p.160 e 163.

PEREIRA, Y.C.C. Formação e docência: a construção de um conhecimento integrado no curso de Pedagogia - mobilizando saberes e enfrentando incertezas no Ensino de Ciências Naturais. 2004. 265 f. Tese (Doutorado em Educação) - Centro de Ciências da Educação, Universidade Federal de Santa Catarina, Florianópolis, 2004.

REIS, R. H. Histórico, Tipologias e Proposições sobre a Extensão Universitária no Brasil. Cadernos UnB Extensão: A universidade construindo saber e cidadania. Brasília, 1989. Disponível em: https://periodicos.unb.br/index.php/linhascriticas/article/view/2610. Acesso em: 25 jul. 2020.

SAVIANI, D. Ensino público e algumas falas sobre universidade. 4.ed. São Paulo: Cortez, 1987.

SÍVERES, L.; MENEZES, A. Transcendendo Fronteiras - A Contribuição da Extensão das Instituições Comunitárias de Ensino superior. Santa Cruz do Sul: Edunisc, 2011. p. 53.

VIEIRA, M. G. M.; IZA, O. B.; KORZ, C. FISCHER, J. Agricultura Sustentável: favorecendo ambientes saudáveis e o empoderamento feminino. Revista Educação Popular, Uberlândia, v. 18, n. 2, p. 5, maio/ago. 2019. Disponível em: http://www.seer.ufu.br/index.php/reveducpop/article/view/46405. Acesso em: 27 jul. 2020.

Recebido em: 12/08/2020

Aceito em: 16/04/2021 